С.В. Нєкрасов, А.Г. Галузінський, Г.А. Зливка

Харківський начіональний університет Повітряних Сил ім. І. Кожедуба, Харків

\title{
МЕТОДИКА ОБҐРУНТУВАННЯ ТЕХНІЧНОГО ОБРИСУ ТРЕНАЖЕРНИХ ЗАСОБІВ ОЗБРОЄННЯ I ВІЙСЬКОВОЇ ТЕХНІКИ ВІЙСЬК ПРОТИПОВІТРЯНОЇ ОБОРОНИ СУХОПУТНИХ ВІЙСЬК ТА ЇХ ХАРАКТЕРИСТИК
}

\begin{abstract}
Розглянутий один з можливих підходів до обтрунтування технічного обрису тренажерних засобів озброєння і військової техніки військ протиповітряної оборони Сухопутних військ та їх характеристик. На підставі аналізу прочесів навчання, бойової роботи на озброєнні та військової техніки і функціонування реального об'єкту керування (в даному випадку зенітного комплексу) та характеру діяльності оператора щзодо його керування запропонована схема формування раціонального технічного обрису тренажерного засобу. Показано, щчо рішення иієї задачі в методологічному плані вимагає розробки системи моделей, які описують процес бойового функціонування зенітного комплексу при виконанні сукупності бойових завдань в прогнозованих умовах ведення бойових дій, дій оператора з його керування та методик навчання $i$ очінювання операторів. Приводиться алгоритм обгрунтування технічного обрису тренажерних засобів озброєння військ протиповітряної оборони та їх характеристик. Показано, щчо запропонований підхід дозволяє підняти рівень обгрунтованості тактико-технічних вимог і технічних пропозицій зі створення тренажерних засобів нового покоління і структурувати ичей процес у вигляді послідовності взаємопов'язаних процедур, щзо, у свою чергу, дозволить перейти до формалізації основних етапів функціонального і схемотехнічного проектування тренажерних засобів нового покоління.
\end{abstract}

Ключові слова: зенітний комплекс, тренажерний засіб, тактико-технічні характеристики, технічний обрис, структурна схема, принции побудови, методика обгрунтування.

\section{Вступ}

Постановка проблеми. Аналіз збройних конфліктів останніх десятиліть свідчить, що одним 3 основних завдань воєнного протистояння є завоювання переваги у повітрі.

У вирішенні цього завдання провідну роль відіграють засоби повітряного нападу. Широке їх використання дозволяє докорінно змінювати хід бойових дій та здійснювати їх подальшу підтримку. Враховуючи це, постає завдання ефективної боротьби 3 повітряними цілями різних видів та типів. Одним 3 пріоритетних завдань у боротьби з повітряними цілями, яке традиційно покладається на сили та засоби протиповітряної оборони (ППО) Сухопутних військ (CB), є боротьба з маловисотними та малорозмірними цілями.

Зенітні ракетні комплекси (ЗРК) (зенітні гарматно-ракетні комплекси (ЗГРК), переносні зенітні ракетні комплекси (ПЗРК)) (далі - зенітні комплекси) являють собою складні технічні системи. Складність конструкцій бойової техніки, способів іії застосування у сучасних збройних конфліктах, висока напруженість та швидкоплинність протиповітряного бою вимагає від розрахунків (обслуг, екіпажів) зенітних комплексів високого рівня теоретичних знань та стійких практичних навичок. Для досягнення не- обхідного рівня навичок необхідно постійно проводити тренування у бойовій роботі.

Оператори зенітного озброєння приймають, як правило, найбільш складні і відповідальні рішення по управлінню комплексом в стислі терміни, причому від правильності їх дій, вмінь своєчасно знайти і реалізувати вірне в складній ситуації рішення залежить не тільки ефективність виконання завдань, покладених на зенітний комплекс, але в ряді випадків цілісність самого озброєння і безпека людей.

Зростання ролі операторів, пов'язане з необхідністю керування все більш складними динамічними об'єктами, гостро ставить проблему вдосконалення методичних і технічних засобів професійного відбору та підготовки операторів.

Аналіз останніх досліджень і публікацій. Найбільш повно і системно створення тренажерних засобів викладено в роботі [1]. В даній роботі основна увага приділена створенню тренажерних засобів авіаційної техніки, яка має ряд суттєвих відмінностей від зенітного озброєння. При цьому, створення тренажерних засобів розглядається із позицій застосування технологій середини 20-го століття.

Принцип побудови перспективних тренажерних систем підготовки операторів автоматизованих систем управління (АСУ) динамічними об'єктами розглядаються у роботі [2]. Робота фокусується на 
підвищенні ефективності підготовки операторів АСУ шляхом вдосконалення оцінювання дій операторів та адаптації середовища навчання.

В роботі [3] розглядається підготовка стрільців-зенітників з використанням сучасних тренажерних комплексів на прикладі вже створеного тренажеру, не розкриваючи зміст процесу проектування тренажеру.

Отже, завдання обгрунтування технічного обрису тренажерного засобу та його характеристик залишається не вирішеною.

Мета статті - розробка методики обгрунтування технічного обрису тренажерних засобів для ОВТ військ ППО СВ.

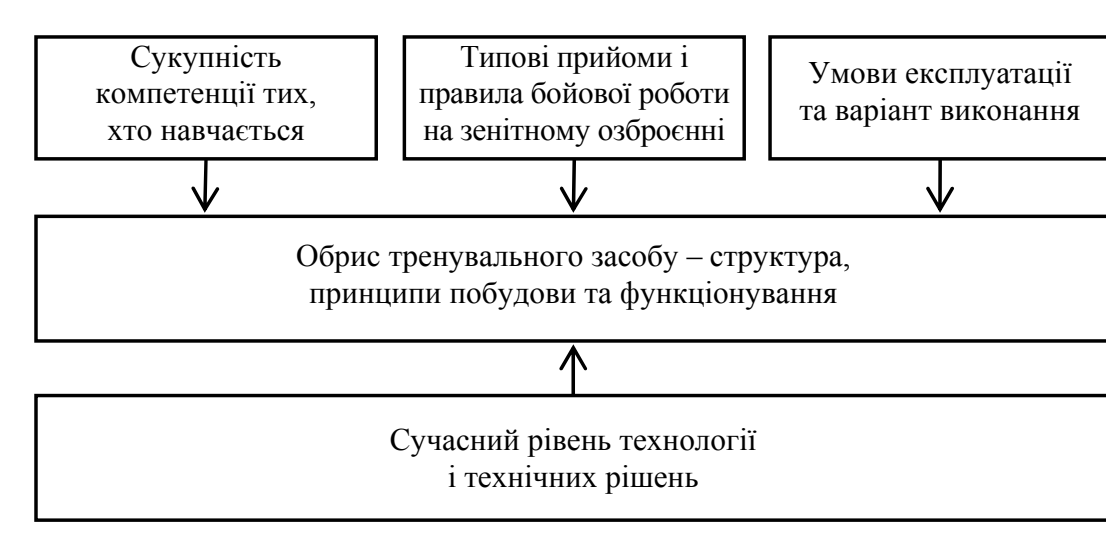

\section{Виклад основного матеріалу}

В загальному випадку, задача обгрунтування технічного обрису тренажерного засобу полягає в знаходженні відображення завдань та функцій, що покладаються на нього, на варіанти їх вирішення за допомогою того чи іншого складу апаратних (технічних) і програмних засобів, що забезпечують мінімальні затрати на розробку і експлуатацію тренажерного засобу (Т3). Синтез раціонального технічного обрису Т3 повинен здійснюватися в процесі виконання комплексу досліджень, направлених на визначення чинників, що впливають на технічний обрис ТЗ. Схему досліджень, направлених на формування раціонального технічного обрису тренажерного засобу, представлено на рис.1.

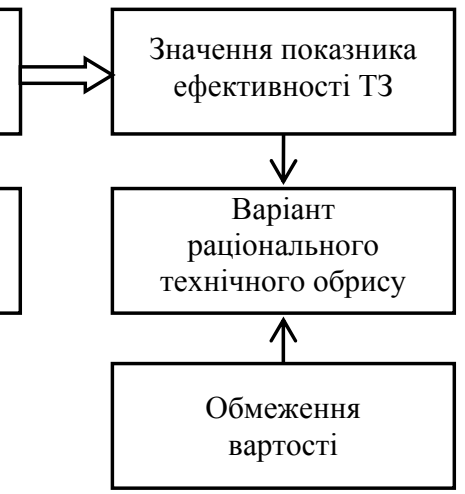

Рис.1. Схема формування раціонального технічного обрису тренажерного засобу

Навчання фахівців військ протиповітряної оборони (ППО) Сухопутних військ (СВ) Збройних Сил (ЗСУ) України здійснюється в рамках навчальних програм (програм бойової підготовки), метою та завданнями яких є формування умінь та вироблення практичних навичок з безаварійної експлуатації зразків озброєння і військової техніки за призначенням. Особливістю ТЗ є поєднання вимог освітнього процесу (сукупність компетенцій тих, хто навчається) та принципів функціонування ЗРК.

Саме на підставі аналізу сукупності компетенцій, які необхідно набути членам розрахунку (обслуги) ЗРК, та прийомів і правил бойової роботи на ЗРК визначаються завдання, які мають бути вирішені за допомогою тренажерного засобу. Ці дані є вихідними для формування технічного обрису ТЗ.

Отже, для визначення вихідних даних для формування технічного обрису ТЗ необхідно дати однозначні відповіді на два питання:

- чому вчити операторів;

- яка повинна застосовуватися методика їх навчання.
Відповідь на перше питання можна отримати в результаті аналізу процесів бойової роботи на озброєнні та військової техніки (ОВТ) і функціонування реального об'єкту керування (в даному випадку зенітного комплексу) та характеру діяльності операторів щодо його керування. При цьому необхідно визначити алгоритм дій оператора, під час ведення бойової роботи в різних ситуаціях, встановити обсяг навичок і рівень компетенцій, формування яких повинно забезпечуватися за допомогою тренажерного засобу (системи), перелік нештатних ситуацій, які повинні відпрацьовуватися, вимоги до глибини формованих навичок та інше.

Відповідь на друге питання визначають шляхи організації і управління тренувальним процесом на основі вивчення властивостей людини-оператора i його можливостей 3 керування об'єктом. Ефективність застосування тренажерів залежить не тільки від ступеня наближення умов тренувань до реальних, а і від методик навчання операторів, які розробляються 3 урахуванням закономірностей формування навичок у тих хто навчається. У програму 
тренувальних вправ повинні входити насамперед найбільш складні критичні ситуації, навички роботи в яких неможливо сформувати в реальних умовах. Крім того, ТЗ повинен дозволяти інструкторові змінювати ситуації, вводити нові або додаткові умови, що ускладнюють керування об'єктом або створюють перешкоди, а також формувати вправи дозовано прогресуючої складності. При цьому навички ранжуються за значимістю; характер завдань, які виконуються в процесі тренування, індивідуалізований 3 урахуванням функціональних обов'язків і можливостей оператора. Отже, визначившись з обсягом навичок і компетенцій, які набуваються тими, хто навчається за допомогою тренажерів, можливо сформулювати завдання для ТЗ. Ці завдання безпосередньо впливають на структуру та принципи побудови тренувальних засобів. В цілому для забезпечення формування і вдосконалення у операторів професійних навичок і вмінь 3 ведення бойової роботи на зенітних комплексах на ТЗ можуть покладатися такі основні завдання:

- моделювання в регульованому (уповільненому, реальному, прискореному) масштабі часу функціонування апаратури і органів керування зенітного комплексу (динаміки його поведінки, роботи бортових систем тощо) і зовнішньої обстановки на засобах спостереження (індикації) об'єкту керування, відповідно до керуючих впливів оператора в нормальних і критичних режимах;

- моделювання фізичних факторів робочого середовища, що викликають у тих хто навчається відчуття, адекватно пов'язані 3 алгоритмом їх діяльності;

- управління процесом навчання і тренування;

- контроль, оцінка та реєстрація діяльності операторів в процесі навчання і тренування;

- наступне поширення інформації, зафіксованої в процесі навчання і тренування, 3 можливістю тимчасової зупинки, повернення на будь-який попередній етап завдання, що відпрацьовується.

На варіанти реалізації Т3 також впливають такі фактори як сучасний рівень технологій і технічних рішень, які можуть бути застосовані при реалізації апаратних (технічних) і програмних засобів тренажеру, та умови експлуатації і варіанти виконання майбутнього тренажеру.

Рівень технологій і технічних рішень визначає загальний (принципіальний) підхід до формування технічного обрису. Наприклад, відтворення функціонування апаратури і органів керування ЗРК за допомогою віртуальних, фізичних моделей або їх поєднання у певному співвідношенні. Умови експлуатації та варіанти виконання ТЗ визначаються, перш за все, різноманітністю сфер їх практичного застосування і технічних рішень, покладених в основу їх побудови, повнотою відтворюваних умов роботи операторів ЗРК, призначенням та способами реалізації Т3. Наприклад, варіанти виконання статичного і динамічного тренажерів будуть суттєво відрізнятися наявністю у складі останнього засобів, що моделюють акселеративні відчуття оператора. Так само класний і польовий варіант тренажеру будуть відрізнятися вимогами до стійкості його апаратури до зовнішніх впливів.

Результатом проведених досліджень може бути структурна схема Т3, опис принципів побудови та функціонування, які складають його технічний обрис. Для реалізації запропонованої схеми досліджень можливо використовувати алгоритм, представлений на рис. 2. Ряд процесів алгоритму, які позначені на схемі значком $\square$, мають підпроцеси (позначені на схемі значком Ш $\square$ ), котрі $є$ невід'ємними складовими свого процесу та розширюють і пояснюють його. Як правило, при розробці Т3 розглядаються декілька варіантів його технічного обрису. Для порівняння отриманих варіантів доцільно використати певний критерій, який би враховував відповідність визначеним завданням, що вирішуються за допомогою Т3 та прийнятим обмеженням щодо вартості розробки та експлуатації тренажеру. Основним критерієм для визначення раціонального технічного обрису тренажерних засобів доцільно обирати критерій “ефективність-вартість”. Оптимізація параметрів структури тренажерного засобу (системи) за критерієм “ефективністьвартість" полягає у вирішені завдання побудови технічної системи з такими параметрами, які забезпечують максимальну ефективність тренажерного засобу (системи) при заданих умовах функціонування та обмеженнях вартості її розробки та експлуатації.

При розробці технічних систем, як правило, доводиться враховувати багато різноманітних вимог, що пред'являються до них. Тому, коли оцінюють або порівнюють декілька варіантів ії побудови, не можна обмежуватися порівнянням тільки по одному з показників, а необхідно приймати до уваги всю їх сукупність. Вибір часткових показників та обгрунтування критерію ефективності тренажерного засобу - тема окремої публікації.

\section{Висновки}

Аналіз підходів до створення тренувальних засобів, навчального й полігонного обладнання для фахівців військ ППО СВ свідчить, що однією $з$ основних причин, що знижує ефективність їх впровадження у освітній процес є брак єдиної методології їх побудови на основі використання новітніх дидактичних та комп'ютерних технологій і технічних рішень. Аналіз процесу підготовки операторів зенітних засобів, стану розвитку тренажерних засобів, що застосовуються в підготовці фахівців ППО СВ на сучасному етапі, свідчить про високу ефективність 
цього засобу навчання та необхідність розробки i впровадження сучасних тренажерів у освітній процес і професійну підготовку військовослужбовців. На підставі аналізу взаємозв'язків між вимогами до рівня кваліфікації тих, хто навчається, принципами функціонування ЗРК та правилами його експлуатації, вимогами до варіанту виконання тренажерного засобу з одного боку та рівнем розвитку сучасних технологій та проектних рішень формуються вихідні дані для алгоритму формування технічного обрису тренажерного засобу. Використання запропонованого алгоритму дає змогу у логічній послідовності сформувати технічний обрис тренажерного засобу.
Він дає змогу для чіткого розмежуванні етапів створення тренувальних засобів, що позитивно впливає на організацію діяльність 3 їх розробки та на зниження витрати фінансових та матеріальних ресурсів. Отже, запропонована методика дає можливість обгрунтувати раціональний технічний обрис тренажерного засобу, який стане основою під час опрацювання загальних вимог до тренажерів зенітного озброєння. Перспективою подальших досліджень у даному напрямку $є$ розробка методології створення інтегрованих тренажерних систем для комплексного навчання розрахунків (обслуг) зенітних комплексів та тренування підрозділів військ ППО СВ.

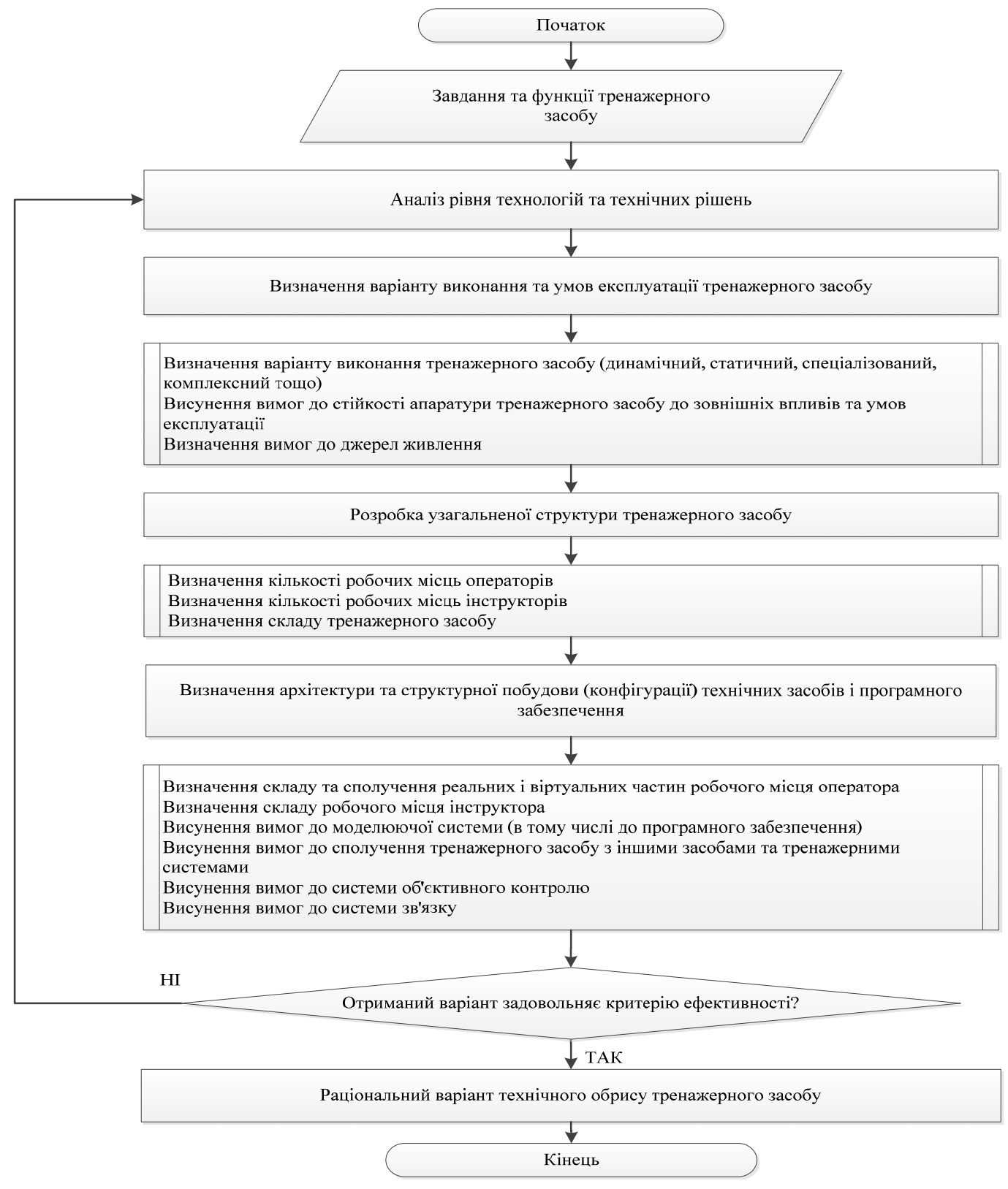

Рис. 2. Алгоритм обгрунтування технічного обрису тренажерних засобів

\section{Список літератури}

1. Шукшунов В.Е. Тренажерные системы / В.Е. Шукшунов, Ю.А. Бакулов, В.Н. Григоренко. - М.: Машиностроение, 1981. -256 с 
2. Принципы построения перспективных тренажерных систем подготовки операторов АСУ динамическими объектами / М.А. Павленко, А.И. Тимочко, Г.С. Степанов, В.Г. Чернов // Сучасні інформаційні технології у сфері безпеки та оборони. - 2014. - № 1. - С. 112-117.

3. Пістряк П.В. Особливості підготовки стрільців-зенітників з використанням сучасних тренажерних комплексів / П.В. Пістряк, В.В. Афанасьєв, Д.О. Торяник // Наука і техніка Повітряних Сил Збройних Сил України. - 2016. № 4(25). - C. 56-59.

4. ЗРК “ОСА-АК” (“ОСА”). Подготовка операторов (специалистов) и боевых расчетов ЗРК “ОСА-АК” (“ОСА”) с использованием учебно-тренировочных средств. - М.: Военное издательство, 1983. - 88 с.

5. Чернов В.Г. Оценка эффективности тренажеров для подготовки офицеров боевого управления командных пунктов / В.Г. Чернов // Системи обробки інформації. - 2015. - № 12. - С. 202-205.

6. ЗРК “КУБ”. Подготовка операторов (специалистов) и боевых расчетов ЗРК “КУБ” с использованием учебнотренировочных средств. - М.: Военное издательство, 1983. - 64 с.

7. Матвієвський О.М. Методичний підхід до обгрунтування характеристик тренажних засобів і систем / O.M. Матвієвський, О.В. Герасименко, Ю.М. Щеблані // Наука і оборона. - 2005. - № 1.- С. 59- 66.

8. Руснак І.С. Методологічні засади створення інтегрованої навчально-тренувальної системи оперативної та бойової підготовки військ / І.С. Руснак, В.Л. Шевченко, Ю.І. Артемов // Наука і оборона. - 2002. - № 2. - С. 29-35.

9. Андрощук О.С. Розробка комп'ютерних тренажерів щодо навчання персоналу державної прикордонної служби України / О.С. Андрощук // Вісник Національної академії Державної прикордонної служби України. - 2014. - № 1. C. $12-26$.

10. Інтегрування тренажних технологій як магістральний напрямок вдосконалення навчально-тренувальної бази бойової підготовки військ / О.М. Матвієвський, В.М. Лушніченко, В.В. Семиглазов, Д.К. Яворський // Наука і оборона. 2010. - № 2. - С. 48-54.

11. Наказ Генерального штабу Збройних Сил України “Інструкція з формування оперативно-стратегічних вимог, оперативно-тактичних та загальних вимог до озброєння та військової техніки Збройних Сил України № 213 від 24.05.2016".

12. Шукшунов В.Е. Тренажерные комплексы и тренажеры : технологии разработки и опыт эксплуатации / В.Е. Шукшунов, В.В. Циблиев, С.И. Потоцкий. - М.: Машиностроение, 2005. - 383 с.

\section{References}

1. Shukshunov, V.E., Bakulov, Y.A. and Grigorenko, V.N. (1981), "Trenazhernie systemi” [Exercise systems], Mechanical Engineering, Moscow, $256 \mathrm{p}$.

2. Pavlenko, M.A., Stepanov, G.S., Timochko, A.I. and Chernov, V.G. (2014), "Pryntsypi postroenyia perspektyvnikh trenazhernikh system podhotovky operatorov ASU dynamycheskymy obektamy" [Principles of construction of perspective training systems for the preparation of ACS operators by dynamic objects], Modern Information Technologies in the Field of Security and Defense, No. 1, pp. 112-117.

3. Pistriak, P.V., Afanasiev, V.V. and Torianyk, D.O. (2016), "Osoblyvosti pidhotovky striltsiv-zenitnykiv z vykorystanniam suchasnykh trenazhernykh kompleksiv" [Features of the anti-aircraft snipers' training with the use of the modern simulation facilities], Science and Technology of the Air Force of Ukraine, No. 4(25), pp. 56-59.

4. ZRK "OSA-AK" ("OSA"), (1983), "Podhotovka operatorov (spetsyalystov) y boevikh raschetov ZRK "OSA-AK" ("OSA") s yspolzovanyem uchebno-trenyrovochnikh sredstv" [Training of Operators (Specialists) and Combat Calculations of SAM "OCA-AK" ("OCA") with the Use of Training and Training Tools], Voennoe izdatelstvo, Moscow, $88 \mathrm{p}$.

5. Chernov, V.G. (2015), "Otsenka effektyvnosty trenazherov dlia podhotovky ofytserov boevoho upravlenyia komandnikh punktov" [Evaluation of the efficiency of simulators for the training of command control officers], Information Processing Systems, No. 12, pp. 202-205.

6. ZRK "KUB" (1983), "Podhotovka operatorov (spetsyalystov) y boevikh raschetov ZRK "KUB" s yspolzovanyem uchebno-trenyrovochnikh sredstv" [Training of operators (specialists) and combat calculations of ZRK "KUB" with the use of training and training facilities], Voennoe izdatelstvo, Moscow, $64 \mathrm{p}$.

7. Matvievsky, O.M., Gerasimenko, O.V. and Shcheblanin, Y.M. (2005), "Metodychnyi pidkhid do obgruntuvannia kharakterystyk trenazhnykh zasobiv i system" [Methodical approach to substantiation of characteristics of training facilities and systems], Science and Defense, No. 1, pp. 59-66.

8. Rusnak, I.S., Shevchenko, V.L. and Artemov, Y.I. (2002), "Metodolohichni zasady stvorennia intehrovanoi navchalnotrenuvalnoi systemy operatyvnoi ta boiovoi pidhotovky viisk" [Methodological bases of creation of the integrated training and training system of operational and combat training of troops], Science and Defense, No. 2, pp. 29-35.

9. Androshchuk, O.S. (2014), "Rozrobka kompiuternykh trenazheriv shchodo navchannia personalu derzhavnoi prykordonnoi sluzhby Ukrainy" [Development of computer simulators for training of the staff of the State Border Guard Service of Ukraine], Bulletin of the National Academy of State Border Guard Service of Ukraine, No. 1, pp. 12-26.

10. Matvievsky, O.M., Lushnichenko, V.M., Semiglazov, V.V. and Yavorsky, D.K. (2010), "Intehruvannia trenazhnykh tekhnolohii yak mahistralnyi napriamok vdoskonalennia navchalno-trenuvalnoi bazy boiovoi pidhotovky viisk" [Integration of training technologies as a main direction of improvement of the training base of combat training of troops], Science and Defense, No. 2, pp. 48-54.

11. The Order of the General Staff of the Armed Forces of Ukraine (2016), "Instruktsiia z formuvannia operatyvnostratehichnykh vymoh, operatyvno-taktychnykh ta zahalnykh vymoh do ozbroiennia ta viiskovoi tekhniky Zbroinykh Syl Ukrainy No. 213 vid 24.05.2016" [Instruction on the formation of operational-strategic requirements, operational-tactical and general requirements for arms and military equipment of the Armed Forces of Ukraine No. 213 dated 24.05.2016].

12. Shukshunov, V.E., Tsibliev, V.V. and Pototsky, S.I. (2005), "Trenazhernie kompleksi i trenazheri : tekhnolohyy razrabotky $i$ opit ekspluatatsyy" [Training complexes and simulators: development technologies and operational experience], Mechanical Engineering, Moscow, 256 p. 


\section{Відомості про авторів:}

Некрасов Сергій Володимирович молодший науковий співробітник Харківського національного університету Повітряних Сил ім. І. Кожедуба, Харків, Україна https://orcid.org/0000-0002-5846-0136

Галузінський Андрій Георгійович старший науковий співробітник Харківського національного університету Повітряних Сил ім. І. Кожедуба, Харків, Україна https://orcid.org/0000-0001-7073-2061

Зливка Геннадій Анатолійович старший викладач

Харківського національного університету Повітряних Сил ім. І. Кожедуба,

Харків, Україна

https://orcid.org/0000-0002-0654-360X
Information about the authors:

Sergiy Nyekrasov

Junior Research

of Ivan Kozhedub Kharkiv National

Air Force University,

Kharkiv, Ukraine

https://orcid.org/0000-0002-5846-0136

\section{Andrii Galuzinskyi}

Senior Research Associate

of Ivan Kozhedub Kharkiv National

Air Force University,

Kharkiv, Ukraine

https://orcid.org/0000-0001-7073-2061

\author{
Hennadii Zlyvka \\ Senior Instructor \\ of Ivan Kozhedub Kharkiv National \\ Air Force University, \\ Kharkiv, Ukraine \\ https://orcid.org/0000-0002-0654-360X
}

\title{
МЕТОДИКА ОБОСНОВАНИЯ ТЕХНИЧЕСКОГО ОБЛИКА ТРЕНАЖЕРНИХ СРЕДСТВ ВООРУЖЕНИЯ И ВОЕННОЙ ТЕХНИКИ ВОЙСК ПРОТИВОВОЗДУШНОЙ ОБОРОНЫ СУХОПУТНЫХ ВОЙСК И ИХ ХАРАКТЕРИСТИК
}

\author{
С.В. Некрасов, А.Г. Галузинский, Г.А. Злывка
}

Рассмотрен один из возможных подходов к обоснованию технического облика тренажерных средств (TC) вооружения и военной техники (BВT) войск противовоздушной обороны (ПВО) Сухопутных войск (CВ) и их характеристик. На основании анализа прочессов обучения, боевой работы на ВВТ и функционирования реального объекта управления (в данном случае зенитного комплекса) и характера деятельности оператора по его управлению предложена схема формирования рационального технического облика тренажерного средства. Показано, что решение этой задачи в методологическом плане требует разработки системы моделей, описывающих прочесс боевого функиионирования зенитного комплекса при выполнении совокупности боевых задач в прогнозируемых условиях ведения боевых действий, действий оператора по его управлению и методик обучения и оценки операторов. Приводится алгоритм обоснования технического очертания тренажерных средств ВВТ войск ПВО СВ и их характеристик. Показано, что предложенный подход позволяет поднять уровень обоснованности тактико-технических требований и технических предложений по созданию тренажерных средств нового поколения и структурировать этот проиесс в виде последовательности взаимосвязанных процедур, что, в свою очередь, позволит перейти к формализации основных этапов функционального и схемотехнического проектирования тренажерных средств нового поколения.

Ключевые слова: зенитный комплекс, тренажерное средство, тактико-технические характеристики, техническое очертание, структурная схема, принцип построения, методика обоснования.

\section{TECHNICAL OUTLINE METHOD OF THE SIMULATOR OF THE WEAPONS AND MILITARY EQUIPMENT OF THE LAND FORCES' ANTI-AIRCRAFT DEFENSE TROOPS AND THEIR CHARACTERISTICS}

\author{
S. Nyekrasov, A. Galuzinskyi, H. Zlyvka
}

One of the possible approaches to the grounding of the training equipment technical outline of the weapons and military equipment (WME) of the Land Forces' air defense troops and their characteristics is considered. On the basis of the analysis of training processes, combat work on WME and the functioning of the real object of control (in this case, the antiaircraft complex) and the nature of the operator's activity to control it, a scheme for the formation of a rational technical outline of the simulator is proposed. It is shown that the solution of this problem in the methodological plan requires the development of a system of models that describe the combat operation process of the antiaircraft complex when performing a set of combat tasks in the predicted conditions of combat operations, operator actions to manage it, and methods of training and evaluation of operators. The algorithm of justification of the technical outline of the training equipment of the WME of the Land Forces' the air defense troops and their characteristics is presented. It is shown that the proposed approach allows to raise the level of validity of tactical and technical requirements and technical proposals for the creation of new generation training facilities and to structure this process in the form of a sequence of interrelated procedures, which, in turn, will allow to proceed to the development of techniques and formalizations of the main stages of functional and schematic design of new generation training equipment. The level of technology and technical solutions determines the general (principled) approach to the formation of the technical outline. For example, the simulation of the equipment functioning and anti-aircraft missile system controls using virtual, physical models or their combination in a certain ratio.

Keywords: antiaircraft complex, simulator, tactical and technical characteristics, technical outline, structural diagram, principle of construction, methodology of justification. 